\title{
Canagliflozin, a sodium glucose co-transporter 2 inhibitor, improves model-based indices of beta cell function in patients with type 2 diabetes
}

\author{
David Polidori • Andrea Mari • Ele Ferrannini
}

Received: 7 November 2013 / Accepted: 29 January 2014 / Published online: 1 March 2014

(C) The Author(s) 2014. This article is published with open access at Springerlink.com

\begin{abstract}
Aims/hypothesis In rodent models of diabetes, treatment with sodium glucose co-transporter 2 (SGLT2) inhibitors improves beta cell function. This analysis assessed the effects of the SGLT2 inhibitor, canagliflozin, on modelbased measures of beta cell function in patients with type 2 diabetes.

Methods Data from three Phase 3 studies were analysed, in which: (Study 1) canagliflozin 100 and $300 \mathrm{mg}$ were compared with placebo as monotherapy for 26 weeks; (Study 2) canagliflozin 100 and $300 \mathrm{mg}$ were compared with placebo as add-on to metformin + sulfonylurea for 26 weeks; or (Study 3) canagliflozin $300 \mathrm{mg}$ was compared with sitagliptin $100 \mathrm{mg}$ as add-on to metformin+ sulfonylurea for 52 weeks. In each study, a subset of patients was given mixed-meal tolerance tests at baseline and study endpoint, and model-based beta cell function parameters were calculated from plasma glucose and C-peptide.
\end{abstract}

Electronic supplementary material The online version of this article (doi:10.1007/s00125-014-3196-x) contains peer-reviewed but unedited supplementary material, which is available to authorised users.

D. Polidori $(\bowtie)$

Janssen Research \& Development, LLC, 3210 Merryfield Row,

San Diego, CA 92121, USA

e-mail: DPolido1@its.jnj.com

A. Mari

Institute of Biomedical Engineering, National Research Council,

Padua, Italy

E. Ferrannini

Department of Clinical and Experimental Medicine, University of

Pisa School of Medicine, Pisa, Italy
Results In Studies 1 and 2, both canagliflozin doses increased beta cell glucose sensitivity compared with placebo. Placebosubtracted least squares mean (LSM) (SEM) changes were 23 (9) and 18 (9) pmol $\mathrm{min}^{-1} \mathrm{~m}^{-2}(\mathrm{mmol} / \mathrm{l})^{-1}$ with canagliflozin 100 and $300 \mathrm{mg}$, respectively ( $p<0.002$, Study 1$)$, and 16 (8) and 10 (9) pmol min $\mathrm{m}^{-1} \mathrm{~m}^{-2}(\mathrm{mmol} / \mathrm{l})^{-1}(p<0.02$, Study 2$)$. In Study 3 , beta cell glucose sensitivity was minimally affected, but the insulin secretion rate at $9 \mathrm{mmol} / \mathrm{l}$ glucose increased to similar degrees from baseline with canagliflozin and sitagliptin [LSM (SEM) changes 38 (8) and 28 (9) pmol $\mathrm{min}^{-1} \mathrm{~m}^{-2}$, respectively; $p<0.05$ for both].

Conclusions/interpretation Treatment with canagliflozin for 6 to 12 months improved model-based measures of beta cell function in three separate Phase 3 studies.

Trial registration: Clinicaltrials.gov NCT01081834 (Study 1); NCT01106625 (Study 2); NCT01137812 (Study 3)

Keywords Beta cell function · Canagliflozin · Insulin secretion · SGLT2 - Sodium glucose co-transporter 2 inhibitor · Type 2 diabetes

$\begin{array}{ll}\text { Abbreviations } \\ \text { DPP-4 } & \text { Dipeptidyl peptidase-4 } \\ \text { FPG } & \text { Fasting plasma glucose } \\ \text { FS } & \text { Frequently sampled } \\ \text { GLP-1 } & \text { Glucagon-like peptide-1 } \\ \text { ISR } & \text { Insulin secretion rate } \\ \text { LSM } & \text { Least squares mean } \\ \text { mITT } & \text { Modified intent-to-treat } \\ \text { MMTT } & \text { Mixed-meal tolerance test } \\ \text { MPG }_{0-3} \text { h } & \text { Mean plasma glucose during the 3 h } \\ & \text { postprandial period } \\ \text { OGIS } & \text { Oral glucose insulin sensitivity } \\ \text { OGIS }_{\mathrm{c}} & \text { UGE-corrected OGIS values } \\ \text { SGLT2 }_{\text {UGE }} & \text { Sodium glucose co-transporter 2 } \\ \text { Urinary glucose excretion }\end{array}$




\section{Introduction}

Defects in beta cell function, including reduced insulin secretion and reduced efficiency of proinsulin conversion to insulin, are key pathophysiological factors underlying the hyperglycaemia of patients with type 2 diabetes mellitus $[1,2]$. Declining beta cell function is a major contributing factor to the progressive nature of type 2 diabetes, with many patients eventually requiring insulin therapy to achieve and maintain glycaemic control [3, 4]. Glucose-lowering agents, which in addition to lowering plasma glucose levels, can improve beta cell function or slow the progression of beta cell dysfunction, may be useful for the long-term management of type 2 diabetes [1].

Pharmacological inhibition of the sodium glucose cotransporter 2 (SGLT2) is a novel approach to lowering plasma glucose in individuals with hyperglycaemia. SGLT2 inhibitors block renal glucose reabsorption and lower the renal threshold for glucose, thereby markedly increasing urinary glucose excretion (UGE) $[5,6]$. Studies in animals have shown that beta cell function is restored when normoglycaemia is achieved by treatment with SGLT2 inhibitors [7-10]. The improvements in beta cell function observed in animal models are believed to be secondary to the improved glucose control, rather than due to direct effects of SGLT2 inhibitors on beta cells.

Canagliflozin is an SGLT2 inhibitor developed for the treatment of patients with type 2 diabetes [11-18]. In Phase 3 clinical studies, canagliflozin 100 and $300 \mathrm{mg}$ provided significant improvements in glycaemic control in adult patients with type 2 diabetes, both as monotherapy and as add-on therapy to various background diabetes treatments [11-13, 15-17]. In addition, three clinical studies have evaluated the effects of canagliflozin treatment on measures of beta cell function in patients with type 2 diabetes. The first (Study 1) [16] was a study of canagliflozin 100 and $300 \mathrm{mg}$ monotherapy compared with placebo at 26 weeks. The second (Study 2) [18] studied canagliflozin 100 and $300 \mathrm{mg}$ as add-on therapy to metformin plus a sulfonylurea compared with placebo at 26 weeks; and the third (Study 3) [15] studied canagliflozin $300 \mathrm{mg}$ as add-on therapy to metformin plus a sulfonylurea compared with sitagliptin $100 \mathrm{mg}$ at 52 weeks. In these studies, canagliflozin treatment was generally associated with improvements in surrogate measures of beta cell function, including HOMA-2derived beta cell function (HOMA2-\%B), the proinsulin: C-peptide ratio and the C-peptide AUC:glucose AUC ratio. The current report presents further data from these three studies characterising the effects of canagliflozin treatment on additional indices of beta cell function obtained from the model-based analysis of plasma glucose and C-peptide responses to mixed-meal tolerance tests (MMTTs).

\section{Methods}

Patients and study design Study 1 (canagliflozin monotherapy; ClinicalTrials.gov identifier NCT01081834) [16] and Study 2 (canagliflozin as add-on to metformin and sulfonylurea; ClinicalTrials.gov identifier NCT01106625) [18] were both randomised, double-blind, placebo-controlled, Phase 3 studies with a 26 week core treatment period followed by a 26 week extension period; findings on beta cell function from the core treatment periods are reported here. Study 3 (ClinicalTrials.gov identifier NCT01137812) [15] was a 52 week, randomised, double-blind, active-controlled, Phase 3 study comparing canagliflozin $300 \mathrm{mg}$ with sitagliptin $100 \mathrm{mg}$ as add-on therapy to metformin plus sulfonylurea. Details of study design, including patient inclusion and exclusion criteria, have been previously reported $[15,16,18]$. For all three studies, key aspects of study design, eligibility criteria and patient populations are summarised in Table 1.

These studies were conducted in accordance with the ethical principles detailed in the Declaration of Helsinki, and are consistent with good clinical practice and applicable regulatory requirements. Approval of the study protocols and amendments was obtained from institutional review boards and independent ethics committees of the participating centres. All patients provided informed written consent prior to participation.

Randomisation and study treatments In Studies 1 and 2, patients were randomly assigned to receive daily oral doses of canagliflozin 100 or $300 \mathrm{mg}$ or placebo (1:1:1); randomisation was stratified according to whether individuals had participated in the frequently sampled (FS)-MMTT (Studies 1 and 2), and whether they were taking glucose-lowering agents at screening (Study 1) or had begun a glucose-lowering agent adjustment period (Study 2). In Study 3, patients were randomly assigned to receive daily oral doses of canagliflozin $300 \mathrm{mg}$ or sitagliptin $100 \mathrm{mg}$ (1:1). Randomisation was stratified according to whether individuals had participated in the FSMMTT and whether their pre-randomisation $\mathrm{HbA}_{1 \mathrm{c}}$ value was $\geq 9.0 \%$ (75 mmol $/ \mathrm{mol})$.

In Studies 1 and 2, glycaemic rescue therapy with metformin (Study 1) or insulin (Study 2) was initiated at fasting plasma glucose (FPG) $>15.0 \mathrm{mmol} / \mathrm{l}(270 \mathrm{mg} / \mathrm{dl})$ from Day 1 to Week $6,>13.3 \mathrm{mmol} / \mathrm{l}(240 \mathrm{mg} / \mathrm{dl})$ from Week 6 to Week 12 and $>11.1 \mathrm{mmol} / 1$ (200 mg/dl) from Week 12 to Week 26. No glycaemic rescue therapy was provided in Study 3; patients meeting pre-specified glycaemic criteria (same as for Studies 1 and 2 through to Week $26, \mathrm{HbA}_{1 \mathrm{c}}>8.0 \%$ [64 $\left.\mathrm{mmol} / \mathrm{mol}\right]$ after Week 26) were discontinued.

Endpoints and assessments A subset of patients from each study underwent an FS-MMTT on Day 1 and at Week 26 in Studies 1 and 2, and at Week 52 in Study 3. For the Day 1 test, 
Table 1 Summary of study designs and patient populations

\begin{tabular}{|c|c|c|c|c|c|c|c|c|c|c|c|}
\hline \multicolumn{4}{|c|}{ Study characteristics } & \multicolumn{4}{|c|}{ Eligibility criteria } & \multicolumn{4}{|c|}{ mITT population (FS-MMTT subset), $n$} \\
\hline Study & Treatment & Comparator & Duration $^{\mathrm{a}}$ & $\mathrm{Age}^{\mathrm{c}}$ & $\mathrm{HbA}_{1 \mathrm{c}}{ }^{\mathrm{d}}$ & $\mathrm{FPG}^{\mathrm{e}}$ & $e G F R^{f}$ & PBO & CANA 100 & CANA 300 & SITA 100 \\
\hline 1 & Monotherapy [16] & $\mathrm{PBO}$ & $26^{\mathrm{b}}$ & $18-80$ & $7.0-10.0(53-86)$ & $<15.0(270)$ & $\geq 50$ & $192(76)$ & $195(79)$ & $197(80)$ & NA \\
\hline 2 & $\begin{array}{l}\text { Add-on to } \\
\text { MET+SU [18] }\end{array}$ & $\mathrm{PBO}$ & $26^{\mathrm{b}}$ & $18-80$ & $7.0-10.5(53-91)$ & $<15.0(270)$ & $\geq 55^{\mathrm{g}}$ & $156(55)$ & $157(57)$ & $156(56)$ & NA \\
\hline 3 & $\begin{array}{l}\text { Add-on to } \\
\text { MET+SU [15] }\end{array}$ & SITA & 52 & $\geq 18$ & $7.0-10.5(53-91)$ & $<16.7(300)$ & $\geq 55^{\mathrm{g}}$ & NA & NA & $377(125)$ & $378(124)$ \\
\hline
\end{tabular}

${ }^{\mathrm{a}}$ In weeks

${ }^{\mathrm{b}}$ Results from the 26-week core treatment period are reported here; study also included a 26-week extension period

${ }^{\mathrm{c}}$ In years

${ }^{\mathrm{d}}$ In $\%(\mathrm{mmol} / \mathrm{mol})$

e In $\mathrm{mmol} / \mathrm{l}(\mathrm{mg} / \mathrm{dl})$

${ }^{\mathrm{f}}$ In $\mathrm{ml} \mathrm{min}^{-1}\left(1.73 \mathrm{~m}^{2}\right)^{-1}$

$\mathrm{g}$ eGFR $\geq 60 \mathrm{ml} \mathrm{min}^{-1}\left(1.73 \mathrm{~m}^{2}\right)^{-1}$ if required, based on the local MET label

CANA 100, canagliflozin 100 mg; CANA 300, canagliflozin 300 mg; eGFR, estimated GFR; MET, metformin; NA, not applicable; PBO, placebo; SITA 100, sitagliptin $100 \mathrm{mg}$; SU, sulfonylurea

patients took their first dose of study medication after blood samples for the MMTT were collected. For the FS-MMTT at Week 26 (Studies 1 and 2) or Week 52 (Study 3), the last dose of study medication was administered approximately $30 \mathrm{~min}$ before the start of the standard meal. Patients fasted for at least
$8 \mathrm{~h}$ before the start of the FS-MMTT. The standardised meal was given between 07:00 and 10:00 hours, and consisted of two servings of liquid supplement containing approximately $100 \mathrm{~g}$ of total carbohydrates and approximately $2930 \mathrm{~kJ}$ (700 kcal). Water or non-caffeinated energy-free beverages

Table 2 Baseline demographic and disease characteristics for the FS-MMTT subpopulations

\begin{tabular}{|c|c|c|c|c|c|c|c|c|c|c|c|}
\hline \multirow[t]{2}{*}{ Characteristic } & \multicolumn{4}{|l|}{ Study 1} & \multicolumn{4}{|l|}{ Study 2} & \multicolumn{3}{|l|}{ Study 3} \\
\hline & PBO & $\begin{array}{l}\text { CANA } \\
100\end{array}$ & $\begin{array}{l}\text { CANA } \\
300\end{array}$ & Total & PBO & $\begin{array}{l}\text { CANA } \\
100\end{array}$ & $\begin{array}{l}\text { CANA } \\
300\end{array}$ & Total & $\begin{array}{l}\text { CANA } \\
300\end{array}$ & $\begin{array}{l}\text { SITA } \\
100\end{array}$ & Total \\
\hline$n$ & 61 & 64 & 68 & 193 & 53 & 56 & 54 & 163 & 117 & 117 & 234 \\
\hline \multicolumn{12}{|l|}{$\operatorname{Sex}, n(\%)^{\mathrm{a}}$} \\
\hline Men & $29(48)$ & $19(30)$ & $33(49)$ & $81(42)$ & $30(57)$ & $28(50)$ & $26(48)$ & $84(52)$ & $66(56)$ & $64(55)$ & $130(56)$ \\
\hline Women & $32(53)$ & $45(70)$ & $35(52)$ & $112(58)$ & $23(43)$ & $28(50)$ & $28(52)$ & $79(49)$ & $51(44)$ & $53(45)$ & $104(44)$ \\
\hline Age, years & $58 \pm 12$ & $56 \pm 10$ & $55 \pm 12$ & $56 \pm 11$ & $56 \pm 9$ & $57 \pm 11$ & $55 \pm 8$ & $56 \pm 9$ & $58 \pm 9$ & $57 \pm 8$ & $57 \pm 9$ \\
\hline \multicolumn{12}{|l|}{ Race, $n(\%)^{\mathrm{a}}$} \\
\hline White & $49(80)$ & $46(72)$ & $56(82)$ & $151(78)$ & $43(81)$ & $51(91)$ & $42(78)$ & $136(83)$ & $79(68)$ & $80(68)$ & $159(68)$ \\
\hline Black/African-American & $4(7)$ & $10(16)$ & $6(9)$ & $20(10)$ & $4(8)$ & 0 & $6(11)$ & $10(6)$ & $20(17)$ & $15(13)$ & $35(15)$ \\
\hline Asian & $1(2)$ & 0 & $1(2)$ & $2(1)$ & $1(2)$ & $1(2)$ & 0 & $2(1)$ & $7(6)$ & $4(3)$ & $11(5)$ \\
\hline Other $^{b}$ & $7(12)$ & $8(13)$ & $5(7)$ & $20(10)$ & $5(9)$ & $4(7)$ & $6(11)$ & $15(9)$ & $11(9)$ & $18(15)$ & $29(12)$ \\
\hline $\mathrm{HbA}_{1 \mathrm{c}}, \%$ & $7.7 \pm 0.9$ & $8.0 \pm 0.9$ & $7.9 \pm 0.9$ & $7.9 \pm 0.9$ & $8.1 \pm 0.8$ & $8.2 \pm 1.0$ & $8.3 \pm 1.1$ & $8.2 \pm 1.0$ & $8.0 \pm 0.9$ & $8.1 \pm 0.9$ & $8.1 \pm 0.9$ \\
\hline $\mathrm{HbA}_{1 \mathrm{c}}, \mathrm{mmol} / \mathrm{mol}$ & $61 \pm 9.8$ & $64 \pm 9.8$ & $63 \pm 9.8$ & $63 \pm 9.8$ & $65 \pm 8.7$ & $66 \pm 10.9$ & $67 \pm 12.0$ & $66 \pm 10.9$ & $64 \pm 9.8$ & $65 \pm 9.8$ & $65 \pm 9.8$ \\
\hline FPG, mmol/1 & $9.0 \pm 2.1$ & $9.7 \pm 2.3$ & $9.3 \pm 2.1$ & $9.3 \pm 2.2$ & $9.7 \pm 2.3$ & $10.0 \pm 2.4$ & $9.7 \pm 2.4$ & $9.8 \pm 2.4$ & $8.8 \pm 2.2$ & $8.8 \pm 2.4$ & $8.8 \pm 2.3$ \\
\hline Body weight, $\mathrm{kg}$ & $93 \pm 17$ & $87 \pm 20$ & $90 \pm 22$ & $90 \pm 20$ & $90 \pm 22$ & $93 \pm 21$ & $92 \pm 19$ & $92 \pm 21$ & $84 \pm 20$ & $88 \pm 21$ & $86 \pm 21$ \\
\hline Waist circumference, $\mathrm{cm}$ & $110 \pm 13$ & $104 \pm 13$ & $106 \pm 15$ & $107 \pm 14$ & $105 \pm 15$ & $109 \pm 16$ & $108 \pm 14$ & $108 \pm 15$ & $104 \pm 13$ & $106 \pm 13$ & $105 \pm 13$ \\
\hline Duration of diabetes, years & $4.4 \pm 4.5$ & $5.5 \pm 4.3$ & $5.3 \pm 5.5$ & $5.1 \pm 4.8$ & $10.5 \pm 6.7$ & $9.6 \pm 6.1$ & $8.9 \pm 5.4$ & $9.7 \pm 6.1$ & $9.9 \pm 6.4$ & $10.1 \pm 6.8$ & $10.0 \pm 6.6$ \\
\hline
\end{tabular}

Data are mean \pm SD unless otherwise indicated

${ }^{\text {a }}$ Percentages may not total $100 \%$ due to rounding

${ }^{\mathrm{b}}$ Includes American Indian or Alaska Native, Native Hawaiian or other Pacific Islander, multiple, other or not reported

PBO, placebo; CANA 100, canagliflozin 100 mg; CANA 300, canagliflozin 300 mg; SITA 100, sitagliptin 100 mg 


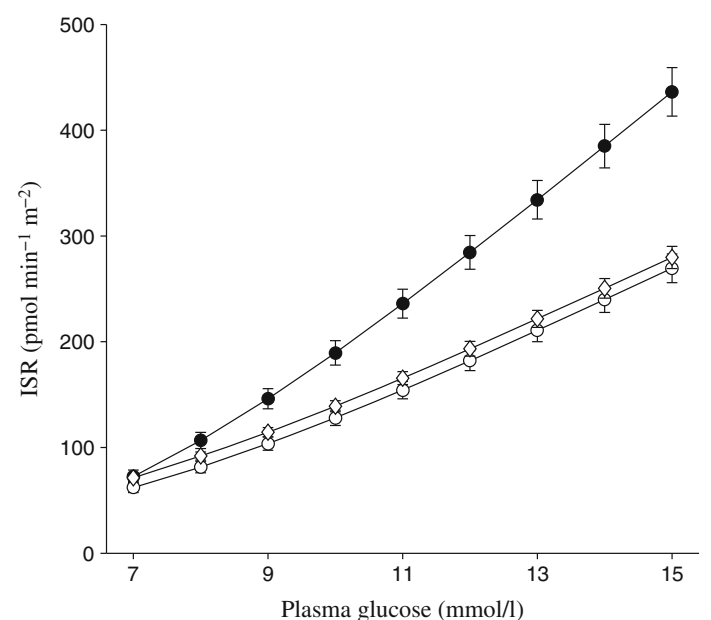

Fig. 1 Baseline (pretreatment) relationship between insulin secretion and plasma glucose concentrations (Studies 1 to 3 ). Black circles, untreated (Study 1; $n=193$ ); white circles, metformin+sulfonylurea (Study 2; $n=163$ ); white diamonds, metformin + sulfonylurea (Study $3 ; n=234$ ). Values are mean \pm SEM and include all patients studied at the baseline visit in each study

could be consumed without restriction. The entire meal was to be completed within a 15 min period.

During the FS-MMTT, blood samples were collected for the measurement of glucose, insulin and C-peptide $15 \mathrm{~min}$ before and immediately prior to the start of the meal, and at 30 , $60,90,120$ and $180 \mathrm{~min}$ after the meal. Patients were asked to empty their bladders immediately prior to collection of the first blood sample. Urine was then collected over the interval from $15 \mathrm{~min}$ before the meal through to $180 \mathrm{~min}$ after the meal for the measurement of UGE. In Study 3, mean plasma glucose during the $3 \mathrm{~h}$ postprandial period $\left(\mathrm{MPG}_{0-3 \mathrm{~h}}\right)$ was calculated as the AUC for the plasma glucose profile (calculated by the trapezoid rule) divided by the $3 \mathrm{~h}$ time interval.

Modelling analysis Beta cell function was assessed from the FS-MMTT using a model that describes the relationship between insulin secretion and glucose concentration, and which has previously been described in detail $[19,20]$. The model expresses insulin secretion (in pmol $\mathrm{min}^{-1} \mathrm{~m}^{-2}$ ) as the sum of two components. The first of these components consists of a dose-response function relating the insulin secretion rate and the absolute glucose concentration at any time point during the MMTT. Characteristic parameters of the dose-response function are the mean slope over the observed glucose range, denoted as beta cell glucose sensitivity, and the insulin secretion rate (ISR) at a fixed glucose level of $9 \mathrm{mmol} / \mathrm{l}$ (i.e. ISR at $9 \mathrm{mmol} / \mathrm{l}$ glucose). The dose-response function is modulated by a potentiation factor encompassing several potentiating
Fig. 2 (a-c) Plasma glucose, (d-f) C-peptide and (g-i) insulin concentrations, and $(\mathbf{j}-\mathbf{l})$ ISR per plasma glucose values in Study 1 . Black circles, baseline; white circles, Week 26. Values are mean \pm SEM for placebo $(\mathbf{a}, \mathbf{d}, \mathbf{g}, \mathbf{j})$, canagliflozin $100 \mathrm{mg}$ $(\mathbf{b}, \mathbf{e}, \mathbf{h}, \mathbf{k})$ and canagliflozin $300 \mathrm{mg}(\mathbf{c}, \mathbf{f}, \mathbf{i}, \mathbf{l})$ a

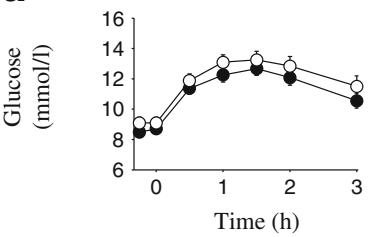

d

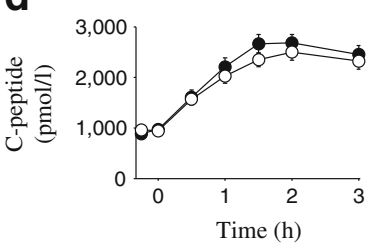

g

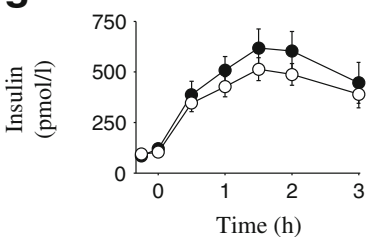

j

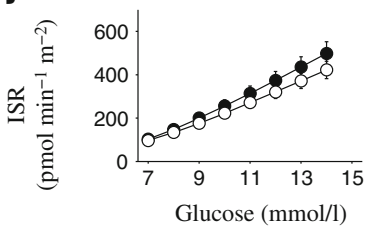

b

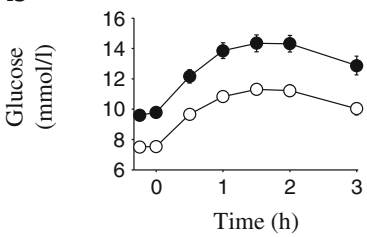

e

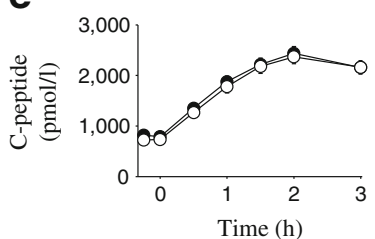

h

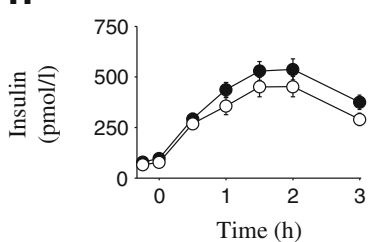

k

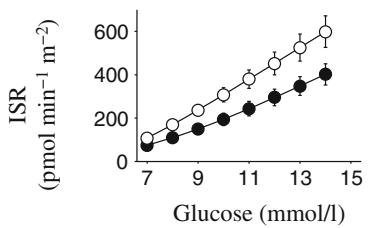

C

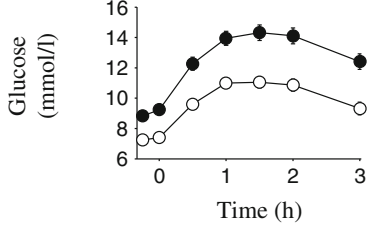

$\mathbf{f}$

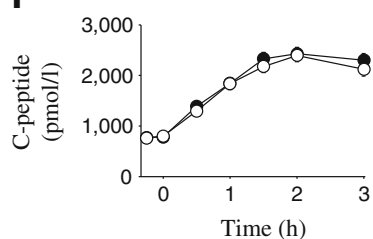

i

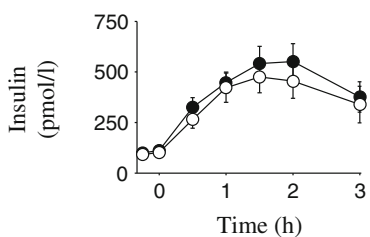

I

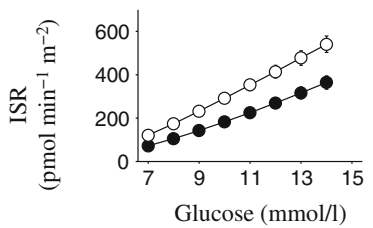


Fig. 3 (a-c) Plasma glucose, (d-f) C-peptide and (g-i) insulin concentrations, and $(\mathbf{j}-\mathbf{l})$ ISR per plasma glucose values in Study 2 . Black circles, baseline; white circles, Week 26. Values are mean \pm SEM for placebo (a, d, g, j), canagliflozin $100 \mathrm{mg}$ $(\mathbf{b}, \mathbf{e}, \mathbf{h}, \mathbf{k})$ and canagliflozin $300 \mathrm{mg}(\mathbf{c}, \mathbf{f}, \mathbf{i}, \mathbf{l})$ a

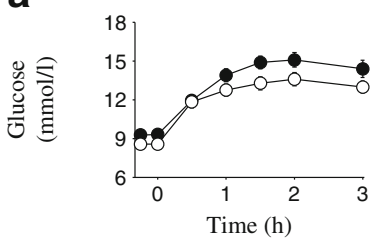

d

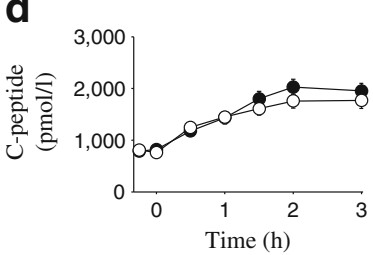

g
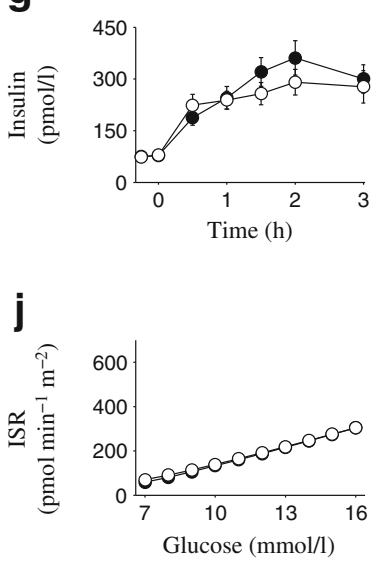

b

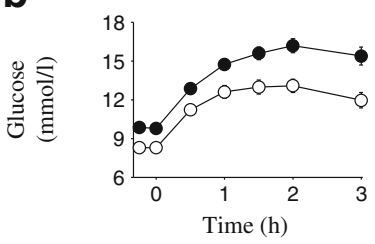

e

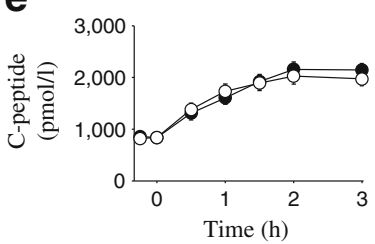

h

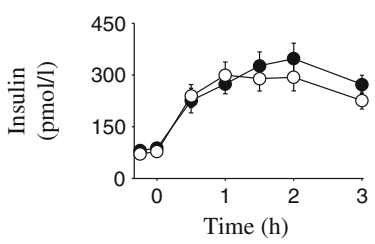

k

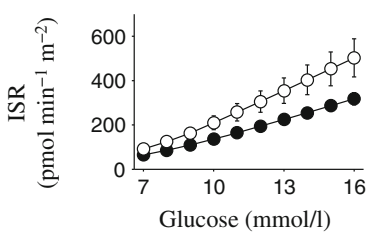

C

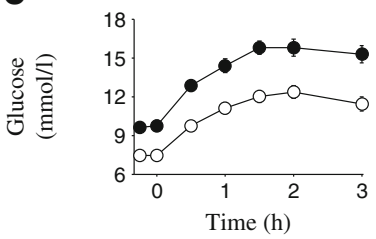

f

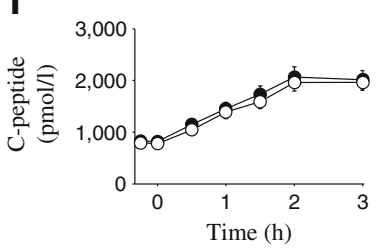

i

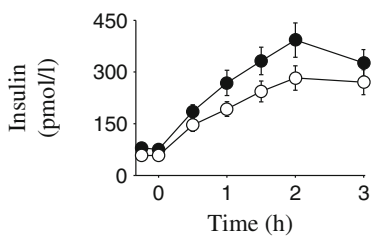

I

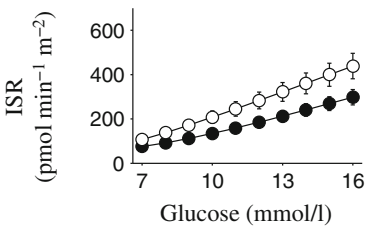

mechanisms (e.g. prolonged exposure to hyperglycaemia, non-glucose substrates, gastrointestinal hormones and neural modulation), which is set to be a positive function of time and is constrained to average unity during the experiment. The second insulin secretion component, termed the derivative component, represents the dependence of insulin secretion on the rate of change of glucose concentration and is determined by a single parameter, denoted as rate sensitivity, that is related to early insulin release [21].

The model parameters were estimated from glucose and C-peptide concentrations by regularised least squares, as previously described [19]. The regularisation process involves a choice of smoothing factors. These were selected to obtain glucose and C-peptide model residuals with SDs close to the expected measurement error ( $\sim 1 \%$ for glucose, $\sim 4 \%$ for C-peptide). The ISR was calculated from the model every $5 \mathrm{~min}$. The integral of insulin secretion during the $3 \mathrm{~h}$ MMTT was denoted as total insulin secretion, and insulin clearance was calculated by dividing total insulin secretion by plasma insulin AUC. Insulin clearance was calculated only for participants with at least five measurements of plasma insulin during the MMTT.

Insulin sensitivity was estimated from the MMTT data using the oral glucose insulin sensitivity (OGIS) index as previously described $[22,23]$. However, because this index does not account for the insulin-independent glucose lowering occurring due to UGE in canagliflozin-treated participants, the OGIS index will tend to overestimate improvements in insulin sensitivity in canagliflozin-treated participants. To account for this, UGE-corrected OGIS values $\left(\mathrm{OGIS}_{\mathrm{c}}\right)$ were calculated by subtracting renal glucose clearance (calculated as UGE divided by plasma glucose AUC during the MMTT) from the OGIS value to provide a more appropriate index of insulin sensitivity for assessing the effects of canagliflozin treatment.

Statistical analyses Results for all model parameters are presented for all patients in the modified intent-to-treat (mITT) analysis set (i.e. all randomised patients who received $\geq 1$ dose of study drug) with MMTT data at baseline and study endpoint. Statistical analyses for ISR at $9 \mathrm{mmol} / 1$ glucose, beta cell glucose sensitivity, OGIS, UGE, total insulin secretion and insulin clearance were performed using ANCOVA models, with the model parameter as the response variable, the baseline parameter value and baseline glycaemic control (binary value assessing whether baseline $\mathrm{HbA}_{1 \mathrm{c}}$ was $<9.0 \%$ [75 mmol/mol] $)$ as covariates, and treatment as the experimental factor. The distribution of values for beta cell glucose sensitivity and the 
a

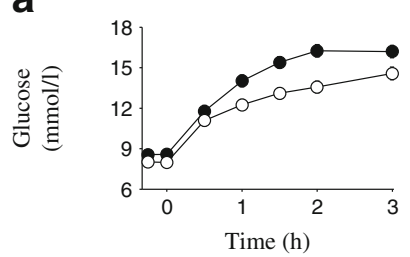

b

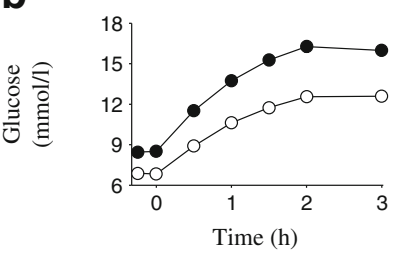

C

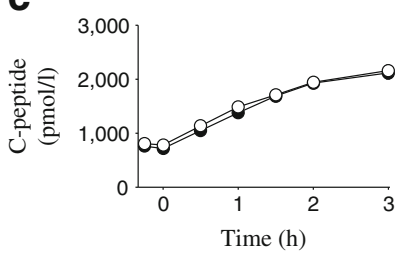

e

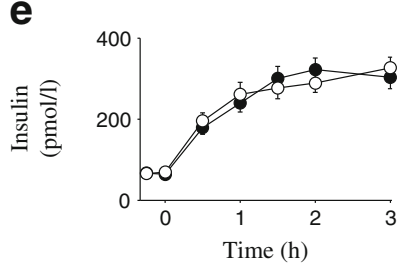

g

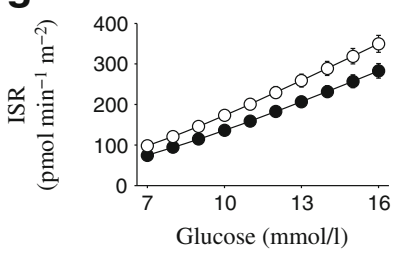

d

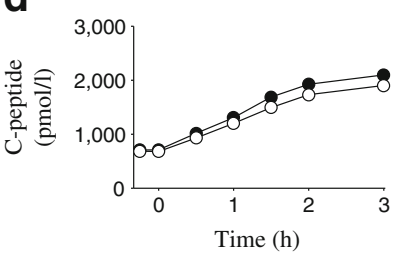

f

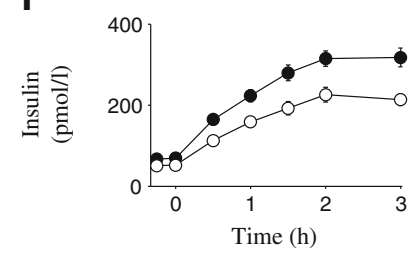

h

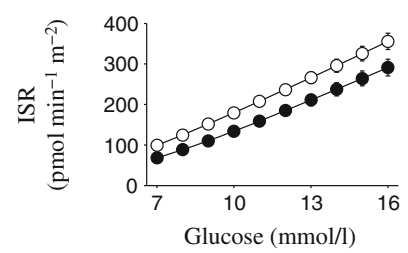

Fig. 4 (a, b) Plasma glucose, $(\mathbf{c}, \mathbf{d})$ C-peptide and $(\mathbf{e}, \mathbf{f})$ insulin concentrations, and (g, h) ISR per plasma glucose in Study 3. Black circles, baseline; white circles, Week 52 . Values are mean \pm SEM for sitagliptin $100 \mathrm{mg}(\mathbf{a}, \mathbf{c}, \mathbf{e}, \mathbf{g})$ and canagliflozin $300 \mathrm{mg}(\mathbf{b}, \mathbf{d}, \mathbf{f}, \mathbf{h})$

OGIS measures were better approximated by a log-normal than a normal distribution, so analyses of these parameters were performed using both original and log-transformed data; for clarity, the results (change in least squares mean $[\Delta \mathrm{LSM}]$ and SEM) are presented in the original scale, but statistical significance testing was performed using the log-transformed values. The distribution of values for the rate sensitivity parameter was highly non-normal, so between-group comparisons were assessed using Kruskal-Wallis tests. In Study 3, similar ANCOVA models to those used for ISR at $9 \mathrm{mmol} / \mathrm{l}$ glucose were used for comparison of FPG, $\mathrm{MPG}_{0-3} \mathrm{~h}$ and peak postprandial plasma glucose concentrations. Differences between treatments were considered statistically significant at $p<0.05$.

\section{Results}

Patient disposition and baseline characteristics Baseline demographic and disease characteristics for patients in the

FS-MMTT subpopulations are summarised in Table 2. The characteristics of these patients are similar to those observed in the overall population in each study $[15,16,18]$. The baseline relationship between ISR and plasma glucose in each of the three studies is shown in Fig. 1. Consistent with the well established progressive nature of beta cell failure in type 2 diabetes, baseline beta cell function was better in patients in Study 1 than in the patients with longer duration of diabetes evaluated in Studies 2 and 3; this is shown by the steeper slope for the relationship between ISR and plasma glucose in Study 1 compared with Studies 2 and 3. Within each study, baseline plasma glucose, insulin and C-peptide profiles, and the corresponding ISR-plasma glucose relationships at baseline were generally similar between the different treatment groups, with the exception of the placebo group in Study 1, which had modestly lower mean plasma glucose concentrations and modestly higher plasma C-peptide concentrations than the two canagliflozin groups, leading to a shift in the mean relationship between baseline ISR and plasma glucose concentration in the placebo compared with the canagliflozin groups (Figs 2, 3, 4).

Effects of canagliflozin treatment on $\mathrm{Hb} A_{10}$ body weight and waist circumference As previously reported [15, 16, 18], in each of the three studies canagliflozin treatment reduced $\mathrm{HbA}_{1 \mathrm{c}}$, body weight and waist circumference. Greater reductions were observed for all three of these measures with canagliflozin treatment than with placebo (Studies 1 and 2) or sitagliptin (Study 3). The changes in these measures in the subset of patients with MMTT data (Table 3) were similar to the changes observed in the complete studies.

Effects of canagliflozin treatment on UGE, fasting and postprandial glucose, and insulin and C-peptide In each of the three studies, canagliflozin treatment increased UGE (Table 4), resulting in reduced fasting and postprandial glucose concentrations (Figs 2, 3, 4). Despite the decreases in plasma glucose concentrations observed with canagliflozin treatment, C-peptide concentrations were generally similar at baseline and the study endpoint (Week 26 for Studies 1 and 2, Week 52 for Study 3) in canagliflozin-treated patients, whereas in the same patients plasma insulin concentrations tended to be modestly lower at the study endpoint relative to baseline (Figs 2, 3, 4). In the sitagliptin comparator study (Study 3), greater reductions in fasting and postprandial glucose were seen with canagliflozin $300 \mathrm{mg}$ than with sitagliptin $100 \mathrm{mg}$ (electronic supplementary material [ESM] Table 1).

Measures of beta cell function and insulin sensitivity In Study 1, both doses of canagliflozin led to an upward shift in the relationship between ISR and plasma glucose, as well as an increased slope (Fig. 2j-1), whereas a slight downward shift was observed with placebo. The model-assessed parameters 


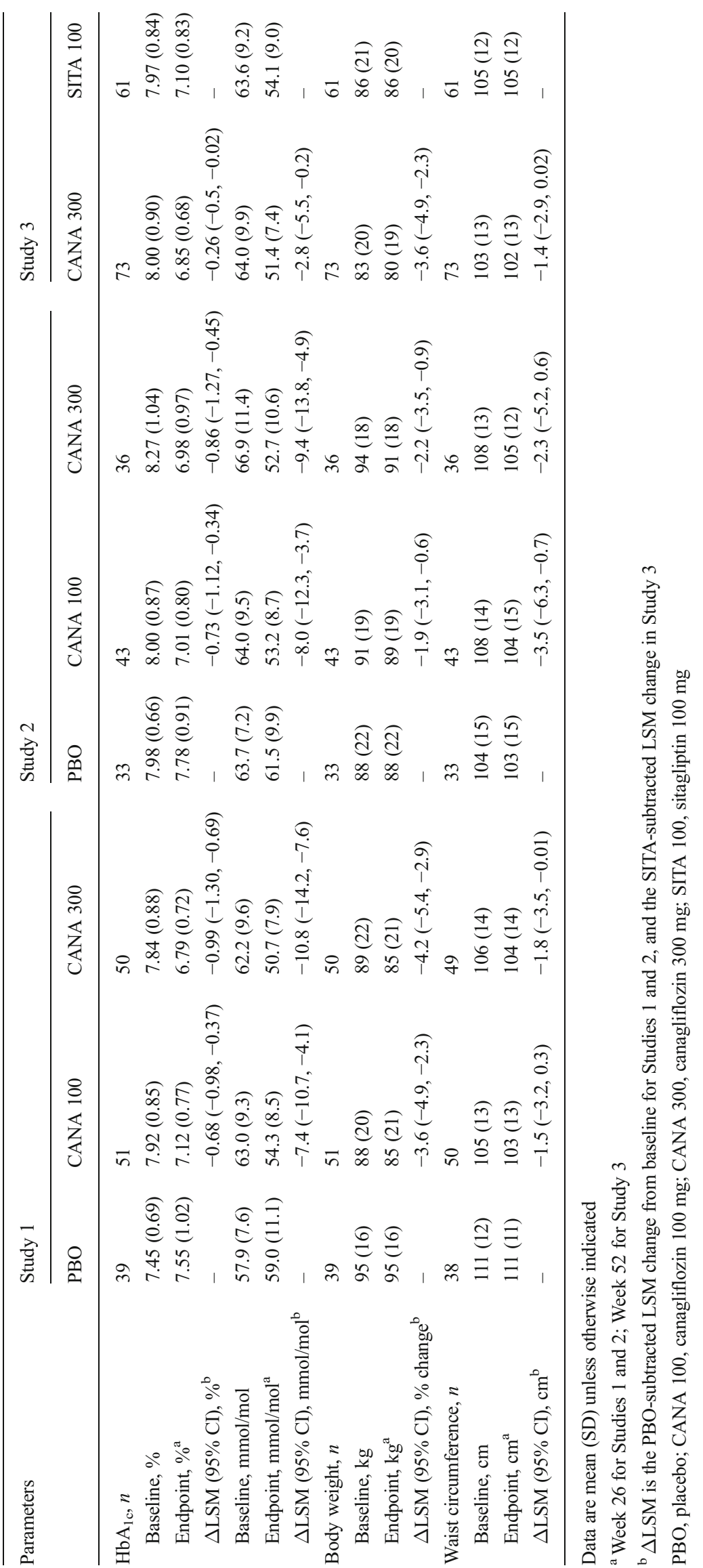


for ISR at $9 \mathrm{mmol} / \mathrm{l}$ glucose and beta cell glucose sensitivity were significantly increased with both doses of canagliflozin (Table 5). Changes in the rate sensitivity parameter varied considerably between patients, with no significant effect of canagliflozin compared with placebo. Total insulin secretion during the MMTT was not statistically significantly different between the canagliflozin and placebo groups. Insulin clearance was increased by approximately $15 \%$ with both doses of canagliflozin compared with placebo (ESM Table 2).

The effects of canagliflozin on beta cell function observed in Study 2 were generally similar to those seen in Study 1, with both doses of canagliflozin leading to an upward shift and steepening of the curve expressing the relationship between ISR and plasma glucose. No change was observed with placebo (Fig. 3j-1). In Study 2, the placebo-subtracted LSM increases in ISR at $9 \mathrm{mmol} / 1$ glucose and in beta cell glucose sensitivity were smaller than those observed in Study 1 (Table 5), with the former (ISR at $9 \mathrm{mmol} / \mathrm{l}$ ) not quite achieving statistical significance ( $p=0.10$ for canagliflozin $100 \mathrm{mg}, p=0.07$ for canagliflozin $300 \mathrm{mg}$ ). Insulin clearance was increased with both doses of canagliflozin compared with placebo, although the increase observed with the $100 \mathrm{mg}$ dose did not reach statistical significance $(p=0.07)$ (ESM Table 2$)$; the increase in insulin clearance observed with the $300 \mathrm{mg}$ dose compared with placebo was approximately $24 \%(p<0.0001)$.

In Study 3, treatment with sitagliptin $100 \mathrm{mg}$ and canagliflozin $300 \mathrm{mg}$ produced similar upward shifts in the relationship between ISR and plasma glucose (Fig. 4g, h). Increases from baseline in ISR at $9 \mathrm{mmol} / \mathrm{l}$ glucose were

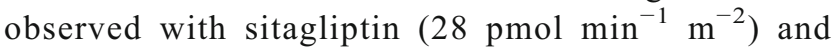

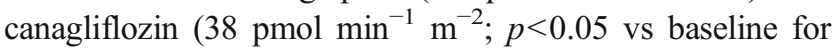
both) (Table 5), with the increase observed with canagliflozin being similar to that observed in Study 2. However, the difference between canagliflozin and sitagliptin was not statistically significant $(p=0.4)$. Only minimal changes in beta cell glucose sensitivity were observed in either treatment group (1-2 $\left.\mathrm{pmol} \mathrm{min}^{-1} \mathrm{~m}^{-2}[\mathrm{mmol} / 1]^{-1}\right)$ in this study, while no differences in rate sensitivity were observed between groups. Consistent with the greater reductions in plasma glucose concentrations in the canagliflozin group, total insulin secretion was reduced with canagliflozin treatment compared with sitagliptin $(p=0.005)$ (Table 5). Insulin clearance was increased by approximately $30 \%$ with canagliflozin $300 \mathrm{mg}$, whereas no change was observed with sitagliptin treatment (ESM Table 2).

Insulin sensitivity, as assessed by the UGE-corrected OGIS values, also improved with canagliflozin treatment (Table 5), with mean values of OGIS $_{c}$ increasing by approximately $15 \%$ in canagliflozin-treated patients (although the differences were not significantly different from placebo in Study 2). As expected, the correction made to OGIS to account for UGE led to smaller increases in the index than those obtained using the uncorrected values.

\section{Discussion}

Progressive loss of beta cell function is a hallmark of type 2 diabetes and contributes to the progressive nature of the disease [1]. Several treatments for type 2 diabetes (e.g. sulfonylureas, meglitinides, glucagon-like peptide-1 [GLP-1] receptor agonists and dipeptidyl peptidase-4 [DPP-4] inhibitors) directly stimulate beta cells to increase insulin release. Using the same methods as in this paper, the DPP-4 inhibitors vildagliptin and sitagliptin $[24,25]$ and the GLP-1 receptor agonists liraglutide and exenatide [26, 27] have all been previously shown to improve indices of beta cell function.

SGLT2 inhibitors lower plasma glucose concentrations through a novel mechanism of action that does not directly affect insulin secretion or insulin sensitivity. SGLT2 inhibition reduces the renal threshold for glucose excretion, leading to increased UGE and thereby lowering plasma glucose concentrations [5, 6]. In several preclinical studies, the reversal of hyperglycaemia by treating hyperglycaemic rodents with SGLT2 inhibitors led to improved beta cell function and mass [7-10]. The present studies demonstrate that sustained treatment with the SGLT2

Table 4 UGE measured during the MMTT $(0-3 \mathrm{~h})$

\begin{tabular}{|c|c|c|c|c|c|c|c|c|}
\hline \multirow[t]{2}{*}{ Urine glucose, $g$} & \multicolumn{3}{|l|}{ Study 1} & \multicolumn{3}{|l|}{ Study 2} & \multicolumn{2}{|l|}{ Study 3} \\
\hline & PBO & CANA 100 & CANA 300 & PBO & CANA 100 & CANA 300 & CANA 300 & SITA 100 \\
\hline Baseline, $n$ & 46 & 46 & 55 & 45 & 52 & 47 & 111 & 107 \\
\hline Mean (SD) & $3.9(7.4)$ & $4.9(7.0)$ & $4.1(5.6)$ & $3.0(4.8)$ & $3.4(5.6)$ & $3.9(4.1)$ & $4.4(5.6)$ & $3.7(4.2)$ \\
\hline Endpoint, $n^{\text {a }}$ & 34 & 53 & 48 & 28 & 42 & 33 & 73 & 51 \\
\hline Mean (SD) & $3.9(8.8)$ & $16.4(15.1)$ & $18.8(19.3)$ & $4.4(12.4)$ & $13.6(14.9)$ & $19.7(23.3)$ & $21.4(34.8)$ & $3.2(4.8)$ \\
\hline$\Delta \operatorname{LSM}(95 \% \mathrm{CI})^{\mathrm{b}}$ & - & $11.3(3.7,19.0)$ & $14.7(7.2,22.3)$ & - & $9.2(0.8,17.6)$ & $15.8(6.8,24.7)$ & $17.7(6.8,28.6)$ & - \\
\hline
\end{tabular}

${ }^{\text {a } W e e k ~} 26$ for Studies 1 and 2; Week 52 for Study 3

${ }^{\mathrm{b}} \triangle \mathrm{LSM}$ is the PBO-subtracted LSM change from baseline (95\% CI) for Studies 1 and 2, and the SITA-subtracted LSM change in Study 3

CANA 100, canagliflozin 100 mg; CANA 300, canagliflozin 300 mg; PBO, placebo; SITA 100, sitagliptin $100 \mathrm{mg}$ 
Table 5 Beta cell function and insulin sensitivity parameters

\begin{tabular}{|c|c|c|c|c|c|c|c|c|}
\hline \multirow[t]{2}{*}{ Parameter } & \multicolumn{3}{|l|}{ Study 1} & \multicolumn{3}{|l|}{ Study 2} & \multicolumn{2}{|l|}{ Study 3} \\
\hline & PBO & CANA 100 & CANA 300 & PBO & CANA 100 & CANA 300 & CANA 300 & SITA 100 \\
\hline$n$ & 39 & 51 & 50 & 33 & 43 & 36 & 73 & 61 \\
\hline \multicolumn{9}{|l|}{$\mathrm{ISR}^{\mathrm{a}}$} \\
\hline Baseline & $200(143)$ & $150(170)$ & 143 (109) & $106(59)$ & 109 (94) & $122(91)$ & $111(59)$ & $115(62)$ \\
\hline Endpoint $^{\mathrm{b}}$ & 175 (117) & $237(171)$ & $232(124)$ & $114(63)$ & $163(62)$ & $172(144)$ & $152(66)$ & $146(87)$ \\
\hline$\Delta \mathrm{LSM}(\mathrm{SEM})^{\mathrm{c}}$ & - & $95(23)$ & $96(24)$ & - & $40(25)$ & $47(26)$ & $38(8)$ & $28(9)$ \\
\hline$p$ value $^{\mathrm{d}}$ & - & $<0.0001$ & $<0.0001$ & - & 0.10 & 0.07 & 0.40 & - \\
\hline \multicolumn{9}{|l|}{ Beta cell GS } \\
\hline Baseline & $58(39)$ & $52(38)$ & $45(23)$ & $28(15)$ & $30(18)$ & $27(20)$ & $26(20)$ & $25(16)$ \\
\hline Endpoint ${ }^{\mathrm{b}}$ & $50(33)$ & $68(65)$ & $59(30)$ & 27 (16) & $46(60)$ & $36(60)$ & $28(15)$ & $29(15)$ \\
\hline$\Delta \operatorname{LSM}(\mathrm{SEM})^{\mathrm{c}}$ & - & $23(9)$ & $18(9)$ & - & $16(8)$ & $10(9)$ & $1(1)$ & $2(2)$ \\
\hline$p$ value $^{\mathrm{d}}$ & - & 0.0007 & 0.002 & - & 0.02 & 0.02 & 0.95 & - \\
\hline \multicolumn{9}{|l|}{ Rate sensitivity $^{\mathrm{f}}$} \\
\hline Baseline & $468(550)$ & $566(810)$ & $471(532)$ & $401(411)$ & $376(521)$ & $218(358)$ & $246(354)$ & $270(406)$ \\
\hline Endpoint $^{\mathrm{b}}$ & $459(518)$ & $412(537)$ & $324(548)$ & $519(574)$ & 364 (494) & $154(323)$ & $265(474)$ & $256(508)$ \\
\hline$\Delta$ Mean $(\mathrm{SEM})^{\mathrm{g}}$ & $-9(78)$ & $-154(120)$ & $-147(101)$ & $118(85)$ & $-12(114)$ & $-64(72)$ & $19(68)$ & $-14(82)$ \\
\hline$p$ value $^{\mathrm{d}}$ & - & 0.55 & 0.17 & - & 0.20 & 0.51 & 0.40 & - \\
\hline \multicolumn{9}{|c|}{ Total insulin secretion ${ }^{\mathrm{h}}$} \\
\hline Baseline & $58(25)$ & $52(19)$ & $54(19)$ & $43(18)$ & $45(20)$ & $42(21)$ & $42(16)$ & $43(17)$ \\
\hline Endpoint ${ }^{\mathrm{b}}$ & $53(20)$ & $50(19)$ & $52(19)$ & $40(16)$ & $45(21)$ & $41(20)$ & $38(15)$ & $44(14)$ \\
\hline$\Delta \operatorname{LSM}(\mathrm{SEM})^{\mathrm{c}}$ & - & $2.6(2.4)$ & $2.5(2.4)$ & - & $3.4(2.6)$ & $1.8(2.7)$ & $-4.8(1.7)$ & - \\
\hline$p$ value $^{\mathrm{d}}$ & - & 0.29 & 0.29 & - & 0.20 & 0.51 & 0.005 & - \\
\hline \multicolumn{9}{|l|}{ OGIS $^{i}$} \\
\hline$n^{\mathrm{j}}$ & 32 & 46 & 43 & 32 & 37 & 32 & 66 & 57 \\
\hline Baseline & $264(45)$ & $250(57)$ & $258(44)$ & $272(46)$ & $250(38)$ & $270(60)$ & $292(58)$ & $293(81)$ \\
\hline Endpoint $^{\mathrm{b}}$ & $265(63)$ & $304(58)$ & $311(57)$ & $298(89)$ & $298(75)$ & $325(68)$ & $356(77)$ & $305(64)$ \\
\hline$\Delta \operatorname{LSM}(\mathrm{SEM})^{\mathrm{c}}$ & - & $50(12)$ & $52(12)$ & - & $11(18)$ & $28(19)$ & $51(12)$ & - \\
\hline$p$ value $^{\mathrm{d}}$ & - & $<0.0001$ & $<0.0001$ & - & 0.46 & 0.06 & $<0.0001$ & - \\
\hline \multicolumn{9}{|l|}{$\mathrm{OGIS}_{\mathrm{c}}{ }^{\mathrm{j}}$} \\
\hline$n^{\mathrm{k}}$ & 32 & 44 & 38 & 32 & 33 & 26 & 64 & 57 \\
\hline Baseline & $263(45)$ & $244(58)$ & $258(45)$ & $269(48)$ & $249(40)$ & $269(65)$ & $286(59)$ & $290(82)$ \\
\hline Endpoint ${ }^{\mathrm{b}}$ & $263(63)$ & $279(60)$ & $289(61)$ & $297(89)$ & $286(81)$ & $304(69)$ & $331(77)$ & $302(65)$ \\
\hline$\Delta \operatorname{LSM}(\mathrm{SEM})^{\mathrm{c}}$ & - & $28(13)$ & $31(13)$ & - & 0.4 (19) & $8(20)$ & $30(12)$ & - \\
\hline$p$ value ${ }^{\mathrm{d}}$ & - & 0.01 & 0.01 & - & 0.98 & 0.54 & 0.02 & - \\
\hline
\end{tabular}

Data are mean (SD) unless otherwise indicated

${ }^{\mathrm{a}}$ In pmol $\mathrm{min}^{-1} \mathrm{~m}^{-2}$ at $9 \mathrm{mmol} / 1$ glucose

${ }^{\mathrm{b}}$ Week 26 for Studies 1 and 2; Week 52 for Study 3

${ }^{\mathrm{c}} \triangle \mathrm{LSM}$ is the PBO-subtracted LSM change from baseline for Studies 1 and 2 and the LSM change from baseline for Study 3. For glucose sensitivity, $\Delta$ LSM values are reported for the untransformed variables, but statistical testing was performed on log-transformed values

${ }^{\mathrm{d}} p$ values vs PBO for Studies 1 and 2, and vs SITA for Study 3

${ }^{\mathrm{e}} \mathrm{In} \mathrm{pmol} \mathrm{min}^{-1} \mathrm{~m}^{-2}(\mathrm{mmol} / \mathrm{l})^{-1}$

${ }^{\mathrm{f}}$ In pmol m ${ }^{-2}(\mathrm{mmol} / \mathrm{l})^{-1}$

g $\Delta$ Mean is the mean change from baseline

${ }^{\mathrm{h}} \mathrm{In} \mathrm{pmol} / \mathrm{m}^{2}$

${ }^{\mathrm{i}} \mathrm{In} \mathrm{ml} \mathrm{min}^{-1} \mathrm{~m}^{-2}$; not corrected for UGE

${ }^{\mathrm{j}} \mathrm{In} \mathrm{ml} \mathrm{min}^{-1} \mathrm{~m}^{-2}$

${ }^{\mathrm{k}}$ The number of patients with OGIS values is smaller than the number of patients with the other measures, as some patients had insufficient insulin and/or UGE measurements to perform the OGIS calculations

CANA 100, canagliflozin 100 mg; CANA 300, canagliflozin 300 mg; GS, glucose sensitivity; PBO, placebo; SITA 100, sitagliptin 100 mg 
inhibitor canagliflozin for 6 to 12 months improved fasting and postprandial measures of beta cell function in humans. The plasma glucose and $\mathrm{HbA}_{1 \mathrm{c}}$ reductions observed in the FSMMTT patient subsets are consistent with the corresponding reductions observed in the overall populations of the three studies $[15,16,18]$. In Study 3, the improvements in beta cell function obtained from the FS-MMTT analysis were similar with canagliflozin and sitagliptin treatment, even though sitagliptin has direct effects on beta cells through the elevation of GLP-1 and glucose-dependent insulinotropic peptide, whereas canagliflozin is not believed to have any direct effects on beta cells. Although both treatments caused similar increases in ISR relative to glucose during the MMTT, the fasting proinsulin: C-peptide ratio was decreased with canagliflozin treatment compared with sitagliptin treatment [15], suggesting that the treatments have different effects on proinsulin processing [28]. The improvements in measures of beta cell function observed in canagliflozin-treated patients are believed to be secondary to improvements in plasma glucose control, rather than direct effects of canagliflozin, as no changes in measures of insulin secretion have been observed in normoglycaemic participants treated with canagliflozin. For example, no notable changes in $24 \mathrm{~h}$ plasma insulin profiles were observed in healthy participants treated with canagliflozin [29] and, in a separate study with an MMTT in healthy participants treated with canagliflozin $300 \mathrm{mg}$ or placebo, no differences in the relationship between ISR and plasma glucose were observed between the canagliflozin and placebo treatment groups [5].

Canagliflozin treatment generally led to greater reductions in plasma insulin concentrations compared with C-peptide concentrations, suggesting that canagliflozin treatment altered insulin and/or C-peptide clearance, with the calculated increases in insulin clearance with canagliflozin treatment generally ranging from approximately $15 \%$ to $30 \%$. The ISRs and the corresponding insulin clearance values calculated in this study were obtained using the assumption that canagliflozin treatment did not alter C-peptide kinetics. Because the kidney is the primary site of C-peptide clearance and canagliflozin acts directly on the kidney, a separate study was performed to assess whether canagliflozin treatment alters C-peptide clearance. This study showed that canagliflozin had only minimal effects on C-peptide clearance $(<4 \%)$, confirming that the deconvolution procedure used to estimate ISR is appropriate in canagliflozin-treated patients [30]. Thus, it is likely that insulin clearance, which is known to be highly variable due to large and variable first-pass hepatic extraction [31], was increased with sustained canagliflozin treatment.

In conclusion, the results from three separate Phase 3 studies demonstrate that sustained treatment with canagliflozin for 6 to 12 months improves measures of beta cell function. It is now important to obtain data from longer term studies to assess whether treatment with canagliflozin can help slow the progressive decline of beta cell function over a longer period.
Acknowledgements The authors thank all investigators, study teams and patients for their participation in these studies. Editorial support was provided by Cherie Koch of MedErgy and was funded by Janssen Global Services, LLC.

Canagliflozin was developed by Janssen Research \& Development, LLC, in collaboration with Mitsubishi Tanabe Pharma Corporation.

The results from Study 1 were previously presented, in part, in abstract form at the 72nd Scientific Sessions of the American Diabetes Association (ADA), 8-12 June 2012, Philadelphia, PA. Results from Study 2 were previously presented, in part, in abstract form at the 48th Annual Meeting of the European Association for the Study of Diabetes (EASD), 1-5 October 2012, Berlin, Germany, and at the 48th Annual Meeting of the German Diabetes Association (DDG), 8-11 May 2013, Leipzig, Germany. Results from Study 3 were previously presented, in part, in abstract form at the 49th Annual Meeting of the EASD, 23-27 September 2013, Barcelona, Spain.

Funding These studies were supported by Janssen Research \& Development, LLC.

Duality of interest AM has acted as a consultant for Boehringer Ingelheim Pharmaceuticals and Eli Lilly, and has received research support from Boehringer Ingelheim Pharmaceuticals. EF has been on advisory panels for AstraZeneca LP, Bristol-Myers Squibb, Boehringer Ingelheim Pharmaceuticals, Sanofi-Aventis, Johnson \& Johnson, GlaxoSmithKline, Novartis Pharmaceuticals and Merck Sharp \& Dohme, and has received research support from Boehringer Ingelheim Pharmaceuticals, Eli Lilly and Merck Sharp \& Dohme. DP is a full-time employee of Janssen Research \& Development, LLC.

Contribution statement DP contributed to the design and conduct of the study, and the analysis and interpretation of the data. AM and EF contributed to the analysis and interpretation of the data. All authors contributed to the writing and reviewing of the manuscript and approved the final version of the manuscript. DP is responsible for the integrity of the work as a whole.

Open Access This article is distributed under the terms of the Creative Commons Attribution License which permits any use, distribution, and reproduction in any medium, provided the original author(s) and the source are credited.

\section{References}

1. Kahn SE (2001) Clinical review 135: the importance of beta-cell failure in the development and progression of type 2 diabetes. J Clin Endocrinol Metab 86:4047-4058

2. Ferrannini E, Gastaldelli A, Miyazaki Y, Matsuda M, Mari A, Defronzo RA (2005) Beta-cell function in subjects spanning the range from normal glucose tolerance to overt diabetes: a new analysis. J Clin Endocrinol Metab 90:493-500

3. Jabbour S (2008) Primary care physicians and insulin initiation: multiple barriers, lack of knowledge or both? Int J Clin Pract 62: 845-847

4. Inzucchi SE, Bergenstal RM, Buse JB et al (2012) Management of hyperglycemia in type 2 diabetes: a patient-centered approach. Position statement of the American Diabetes Association (ADA) and the European Association for the Study of Diabetes (EASD). Diabetes Care 35:1364-1379

5. Polidori D, Sha S, Mudaliar S et al (2013) Canagliflozin lowers postprandial glucose and insulin by delaying intestinal glucose 
absorption in addition to increasing urinary glucose excretion: results of a randomized, placebo-controlled study. Diabetes Care 36:2154 2161

6. Polidori D, Sha S, Ghosh A, Plum-Morschel L, Heise T, Rothenberg P (2013) Validation of a novel method for determining the renal threshold for glucose excretion in untreated and canagliflozin-treated subjects with type 2 diabetes mellitus. J Clin Endocrinol Metab 98:E867-E871

7. Rossetti L, Shulman GI, Zawalich W, Defronzo RA (1987) Effect of chronic hyperglycemia on in vivo insulin secretion in partially pancreatectomized rats. J Clin Invest 80:1037-1044

8. Nunoi K, Yasuda K, Adachi T et al (2002) Beneficial effect of $\mathrm{T}-1095$, a selective inhibitor of renal $\mathrm{Na}+$-glucose cotransporters, on metabolic index and insulin secretion in spontaneously diabetic GK rats. Clin Exp Pharmacol Physiol 29:386-390

9. Katsuno K, Fujimori Y, Ishikawa-Takemura Y, Isaji M (2009) Longterm treatment with sergliflozin etabonate improves disturbed glucose metabolism in KK-A(y) mice. Eur J Pharmacol 618:98-104

10. Liang Y, Arakawa K, Ueta K et al (2012) Effect of canagliflozin on renal threshold for glucose, glycemia, and body weight in normal and diabetic animal models. PLoS ONE 7:e30555

11. Bode B, Stenlof K, Sullivan D, Fung A, Usiskin K (2013) Efficacy and safety of canagliflozin treatment in older subjects with type 2 diabetes mellitus: a randomized trial. Hosp Pract 41:72-84

12. Cefalu WT, Leiter LA, Yoon K-H et al (2013) Efficacy and safety of canagliflozin versus glimepiride in patients with type 2 diabetes inadequately controlled with metformin (CANTATA-SU): 52 week results from a randomised, double-blind, phase 3 non-inferiority trial. Lancet 382:941-950

13. Lavalle-Gonzalez F, Januszewicz A, Davidson J et al (2013) Efficacy and safety of canagliflozin compared with placebo and sitagliptin in patients with type 2 diabetes on background metformin monotherapy: a randomised trial. Diabetologia 56:2582-2592

14. Rosenstock J, Aggarwal N, Polidori D et al (2012) Dose-ranging effects of canagliflozin, a sodium-glucose cotransporter 2 inhibitor, as add-on to metformin in subjects with type 2 diabetes. Diabetes Care $35: 1232-1238$

15. Schernthaner G, Gross JL, Rosenstock J et al (2013) Canagliflozin compared with sitagliptin for patients with type 2 diabetes who do not have adequate glycemic control with metformin plus sulfonylurea: a 52-week, randomized trial. Diabetes Care 36:2508-2515

16. Stenlöf K, Cefalu WT, Kim K-A et al (2013) Efficacy and safety of canagliflozin monotherapy in subjects with type 2 diabetes mellitus inadequately controlled with diet and exercise. Diabetes Obes Metab $15: 372-382$

17. Yale JF, Bakris G, Cariou B et al (2013) Efficacy and safety of canagliflozin in subjects with type 2 diabetes and chronic kidney disease. Diabetes Obes Metab 15:463-473
18. Wilding JP, Charpentier G, Hollander P et al (2013) Efficacy and safety of canagliflozin in patients with type 2 diabetes mellitus inadequately controlled with metformin and sulphonylurea: a randomised trial. Int J Clin Pract 67:1267-1282

19. Mari A, Tura A, Gastaldelli A, Ferrannini E (2002) Assessing insulin secretion by modeling in multiple-meal tests: role of potentiation. Diabetes 51(Suppl 1):S221-S226

20. Mari A, Schmitz O, Gastaldelli A, Oestergaard T, Nyholm B, Ferrannini E (2002) Meal and oral glucose tests for assessment of beta-cell function: modeling analysis in normal subjects. Am J Physiol Endocrinol Metab 283:E1159-E1166

21. Mari A, Ferrannini E (2008) Beta-cell function assessment from modelling of oral tests: an effective approach. Diabetes Obes Metab 10(Suppl 4):77-87

22. Mari A, Pacini G, Murphy E, Ludvik B, Nolan JJ (2001) A modelbased method for assessing insulin sensitivity from the oral glucose tolerance test. Diabetes Care 24:539-548

23. Mari A, Bagger JI, Ferrannini E, Holst JJ, Knop FK, Vilsboll T (2013) Mechanisms of the incretin effect in subjects with normal glucose tolerance and patients with type 2 diabetes. PLoS ONE 8:e73154

24. Mari A, Sallas WM, He YL et al (2005) Vildagliptin, a dipeptidyl peptidase-IV inhibitor, improves model-assessed beta-cell function in patients with type 2 diabetes. J Clin Endocrinol Metab 90:4888-4894

25. Muscelli E, Casolaro A, Gastaldelli A et al (2012) Mechanisms for the antihyperglycemic effect of sitagliptin in patients with type 2 diabetes. J Clin Endocrinol Metab 97:2818-2826

26. Mari A, Degn K, Brock B, Rungby J, Ferrannini E, Schmitz O (2007) Effects of the long-acting human glucagon-like peptide-1 analog liraglutide on beta-cell function in normal living conditions. Diabetes Care 30:2032-2033

27. Mari A, Nielsen LL, Nanayakkara N, Defronzo RA, Ferrannini E, Halseth A (2006) Mathematical modeling shows exenatide improved beta-cell function in patients with type 2 diabetes treated with metformin or metformin and a sulfonylurea. Horm Metab Res 38:838-844

28. Loopstra-Masters RC, Haffner SM, Lorenzo C, Wagenknecht LE, Hanley AJ (2011) Proinsulin-to-C-peptide ratio versus proinsulin-toinsulin ratio in the prediction of incident diabetes: the Insulin Resistance Atherosclerosis Study (IRAS). Diabetologia 54:3047-3054

29. Sha S, Devineni D, Ghosh A et al (2011) Canagliflozin, a novel inhibitor of sodium glucose co-transporter 2, dose dependently reduces calculated renal threshold for glucose excretion and increases urinary glucose excretion in healthy subjects. Diabetes Obes Metab 13:669-672

30. Sha S, Polidori D, Heise T et al (2013) Effect of canagliflozin (CANA) $300 \mathrm{mg}$ on $\mathrm{C}$-peptide clearance $\left(\mathrm{CL}_{\mathrm{Cpep}}\right)$. Diabetes 62: A291-A292, Abstract

31. Radziuk J, Morishima T (1985) New methods for the analysis of insulin kinetics in vivo: insulin secretion, degradation, systemic dynamics and hepatic extraction. Adv Exp Med Biol 189:247-276 